\title{
Research and Software Development of Active Learning Mode for College Students Based on Computer Network
}

\author{
http://dx.doi.org/10.3991/ijet.v11i08.6052 \\ Jingfang $\mathrm{Wu}$ \\ Hunan City University, Hunan, Yiyang, Heshan, China
}

\begin{abstract}
With the development of information technology, especially the fast development of Internet technology, the network technology has expanded to all walks of life. Using Internet to acquire knowledge has become an important means for us. The paper sums up the current status of foreign active learning modes and the problems existing in computer network environment by referring to the relevant literature. What is more, it also further clarifies the basic concepts and connotations of active learning in the computer network environment and active learning itself by researching on its relevant theoretical basis and influential factors as well. "A new active learning mode in computer network environment" is constructed based on the analysis of the relevant factors of active learning in the computer network environment, taking college students as the studying object and the college English course as an example. According to this model, the active learning platform of college English network is designed and developed. The research conclusion is not only theoretically based, but also founded on the concrete practice and the application. Therefore, it is endowed with maneuverability so as to provide a research example for the general teachers.
\end{abstract}

Index Terms-Internet technology; active learning mode; computer network environment; platform of college English

\section{INTRODUCTION}

The 21 st century is the era of knowledge economy that features the innovation and application of knowledge. At the same time, it is also an information age with the network as the basis and information ability as the center, therefore, active learning and life-long learning will be the inevitable developing trend of the era [1]. Psychologist Herbert Geijo has ever pointed out: the illiteracy in the future are no longer those who do not read, but those who do not learn how to take the initiative to learn [2]." Information society has posed higher requirements to the competence of people. From the perspective of learners, they should not acquire all knowledge in accordance with the traditional teaching model with the changes of learning objectives, learning content and learning form. Instead, they are able to flexibly take the initiative to arrange their own learning. It is really a radical change for the form of traditional learning [3]. From the perspective of educators, teachers are no longer dominating in the learning process but the participants and guiders of learning. Network technology, as a prominent representative of the information technology, will exert a profound impact on the traditional teaching mode, teaching content and teaching means.

\section{THE CONCEPT OF ACTIVE LEARNING AND ITS INFLUENCING FACTORS IN THE COMPUTER NETWORK ENVIRONMENT}

\section{A. The concept of active learning}

We can define them as active learning in a narrow sense and in a general sense, respectively.

1. Active learning in a narrow sense: learning to learn

If the active learning is defined from the perspective of a narrow sense, it is the one which enables learners to learn how to study by themselves [4]. In the practical process of education and teaching, teachers will guide students to clarify their learning objectives, master and skillfully use the learning tools, cultivate the learning interest and motivations of learning, as well as help learners to choose learning strategies so as to improve their learning achievements and reach their learning objectives [5].

2. Active learning in a general sense: learn to liberate them

If the active learning is defined in a general sense: it refers to the method that the concept of active learning will be passed to the students so that they are able to take full advantages of active learning ability to develop their own potential in different stages of life so as to achieve lifelong learning object [6]. What is more, it also endows the learners with the critical spirit and creativity so that learning will become an effective tool for learners to liberate themselves and realize the value of life.

\section{B. Factors affecting active learning}

The factors that affect active learning are divided into two types: internal factors and external factors [7]. It mainly takes the matter of fact into consideration that active learning is a kind of learning activity subject to internal factors of learners. At the same time, active learning is not isolated, but is restricted by many external conditions.

1. Internal factors affecting active learning

\section{(1) Sense of self-efficacy}

The concept of self-efficacy was initiated by Bandura, a famous American psychologist and the founder of social learning theory. It refers to that a speculation and judgment on whether an individual has the ability to accomplish a certain action will be used by the individual independently. "Self-efficacy is one of the important motivational factors that influence active learning." 


\section{(2) Attribution}

Attribution is to attribute and sum up the reasons of of behavior by individual. It refers to the process in which the individual makes speculation and judgment of reasons of behavior according to the relevant information and clues [8]. Attribution is a common phenomenon in learning and the learners will consciously or unconsciously make self-evaluation on their own learning achievement or the learning effect in a certain stage and attempt to ascertain the various reasons for the impact on the effectiveness of learning.

\section{(3) Learning motivation}

Learning motivation is the intrinsic motivation and intrinsic reason used to encourage students to participate in learning activities [9]. It is a strong motive force to stimulate and guide students to take the initiative to acquire knowledge, as well as one of the important factors influencing students' active learning. Therefore, it is linked to learning effects.

2. The main external factors that impact on active learning:

\section{(1) Teachers}

It is undoubtedly that, in the current teaching process, teachers play the dominant role in our country and exert important external influence on the active learning of the learners [10]. Teachers should not only impart knowledge and skills to students, but also provide sufficient guidance for learners in the active learning process so as to cultivate learners in terms of learning responsibility and consciousness and guide them towards actively learning.

(2) The modern educational technology

Active learning highlights the main position of students in the learning process while the teachers only play a role of organization and guidance in the process so as to promote students to construct knowledge and process information in a better way [11]. Textbooks are no longer the only learning content as a variety of modern technology in the teaching process are the cognitive tools for students to take the initiative to learn. As a result, students are able to access plentiful language learning materials through other ways but textbooks, such as network.

(3) Social culture

While the active learning theory originates from western culture such that reflecting the values of western concepts, the traditional oriental culture stresses the importance of respecting teachers and that teachers have absolute authority. It is believed that teachers are the source of knowledge, so students are used to the passive learning mode with teachers as the center [12]. As a consequence, most of them rest strongly on teachers. In this connection, given different cultural backgrounds, it is impossible for us to absolutely imitate foreign active learning models. It should be active learning against the background of multiple cultures. It should not only draw experience from foreign active learning model, but also render it suitable for the national cultural background.

\section{SeVERAl ACtive LeARNING Models In Foreign COUNTRIES}

At present, the research of foreign active learning has been continuously carried out for more than 20 years. In terms of the active learning mode, there are several categories in the following content:

\section{A. Active learning model of Winne \& Butler}

Winne \& Butler put forward a more systematic active learning model in 1990s from the perspective of information processing. They think that a complete active learning process is divided into four stages: task definition, goal setting and planning, strategy execution and meta cognitive regulation "[13]. Task stage is the process of clarifying the new learning tasks according to their own knowledge system and analyzing the relevant conditions and factors. The goal setting and planning stage is the process of determining the learning objectives and learning plans according to the teaching requirements and standards. The stage of strategy implementation is the process of learning and producing results according to the specific learning strategies. Metacognitive regulation stage is the analysis and evaluation of learning effectiveness of their own by learners through learning results and the initial learning objectives with the results being feedback to the evaluation result in their own knowledge systems, then the first three stages will be adjusted accordingly[14]. It is shown in Fig.1.

\section{B. The active learning model of Zimmerman}

Zimmerman is an educational psychologist at the City University of New York [15 17]. On the basis of absorbing the thought and theory of the predecessors, he puts forward an active learning model. He has divided the active learning into three stages of forethought phase, performance / volitional control phase and self- reflection phase, which is shown in Fig.2.

\section{The active learning model of McCombs $s$}

The active learning model of McCombs is very representative. In 1989, the active learning model presented in "Active Learning and Academic Achievement [19]: A View of phenomenology" is more detailed and systematic.

McCombs has divided the active learning into three stages: the target design -- planning and strategy selection -- behavior execution and evaluation. In the goal-setting stage, the learners will analyze the task and judge their own abilities with the results being envisioned as well. Afterwards, the learning object will be determined according to these aspects. In the planning and strategy selection stage, the learners will determine learning goals according to their own situation and further refine the learning content so as to develop appropriate plans. What is more, according to different learning contents and planning arrangements, they are able to select appropriate learning strategies [20]. In the behavior execution and evaluation stage, the learners will judge the effectiveness of their final learning results after the implementation of a period of learning plan by recalibrating their behavior and objectives through the self-monitoring and self-emotional regulation.

\section{IV. “A New Active LeARning Mode” Under THE ENVIRONMENT OF COMPUTER NETWORK}

The idea of active learning by adopting the network is gradually formed. Therefore, the new active learning mode under the environment of computer network presented in this study has simplified the existing active learning model so as to facilitate learners and teachers mastering it and lay the foundation for further enriching the content and forms of active learning [21]. At the same time, it also particularly emphasizes on the examination of 


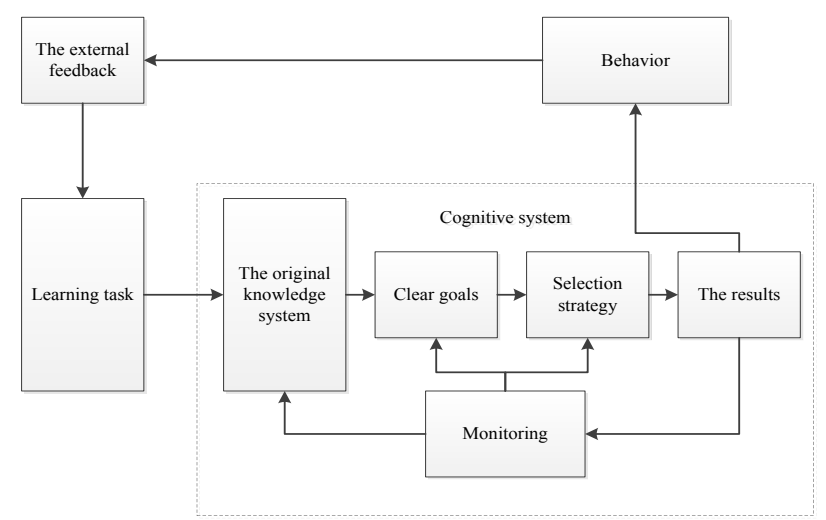

Figure 1. Active learning model of Winne \& Butler

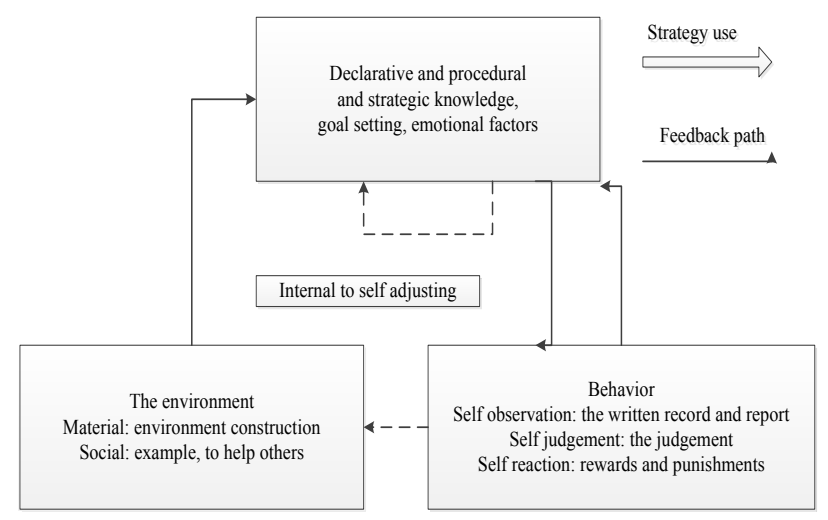

Figure 2. The active learning model of Zimmerman

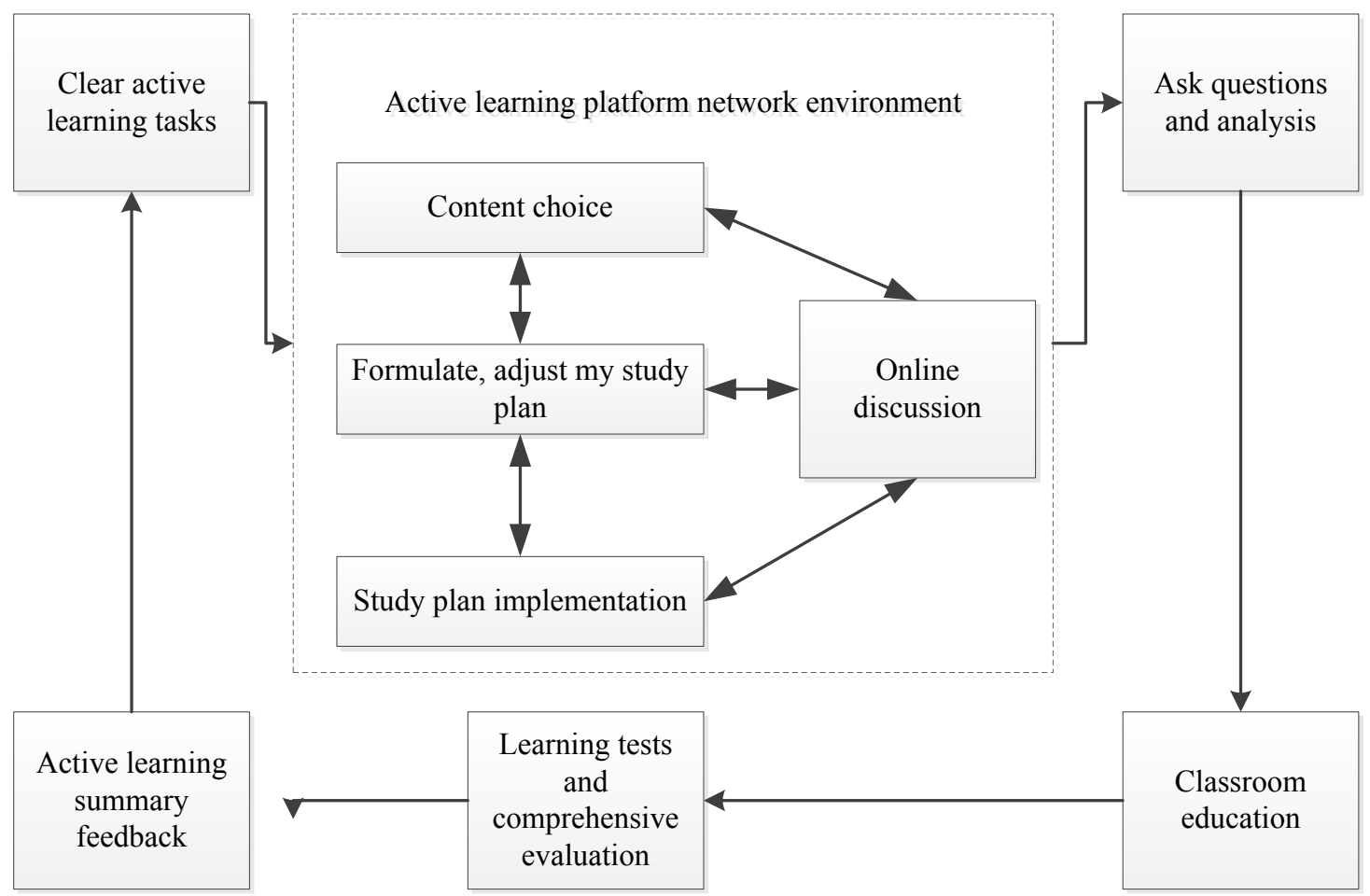

Figure 3. A new active learning mode" under the environment of computer network

the learning effect. On the one hand, the students will carry out self-tests; on the other hand, the teachers should evaluate not only the performance of students, but also the students' learning attitude and learning strategies so as to gradually develop their active learning ability.

The model of "new active learning" in computer network environment put forward in the research is shown in Fig. 3.

The model of active learning in computer network environment includes the following three stages:

First stage is the beginning stage in which the course unit of active learning suitable for computer network environment is selected according to the requirements of the curriculum and in which the active learning objective for this unit is designed and the main task of active learning is clarified.

The second stage is the implementation of active learning in computer network environment. This basically fivepart stage requires students to use the active learning plat- form for active learning. Students can select the learning content according to their own needs, prepare learning plans, implement the learning plan and test the learning effects. In the whole active learning process, students can complete the choice of learning strategies, learning content, and learning plan with classmates and teachers through online discussion. These open contents allow the students to adjust the selection of content for learning with the help of teachers or through peers' exchanging information and discussing with one another. While test results with respect to the learning effect is strictly forbidden from anyone but the teacher and corresponding students, which fully respects the privacy of students.

The third stage is the stage of the problems feedback. Students will submit feedback report during the learning process via Internet or on active learning platform. Teachers will sort out and analyze the problems raised by students. Except for some special problems that can be feedback by online communication, most universal problems are required to be feedback at the fourth stage of collective lecturing. 
PAPER

Research And Software Development of Active LeARning Mode for College Students Based on Compu...

\section{The Design Of Network Active Learning PLATFORM}

A. The development process of network active learning platform for college English courses

The active learning of some courses in the computer network environment is the sum of the teaching content of the course and the teaching activity expressed by the network. Development process is shown in Fig. 4. It mainly includes the determination of college English syllabus, specific content of active learning, overall design of system, prototype design of the network courseware, script writing, material preparation, network curriculum devel- opment, design of teaching environment, design of teaching activities, course trial and evaluation and revision and other processes.

\section{B. The overall design of network active learning plat- form}

In this study, the ASP.NET technology is mainly used to build a network learning platform based on Internet. It adopts the three systematic structure of the Web browser /Web server / database server $(\mathrm{B} / \mathrm{S} / \mathrm{S})$. The overall framework of the network active learning platform is shown in Fig. 5.

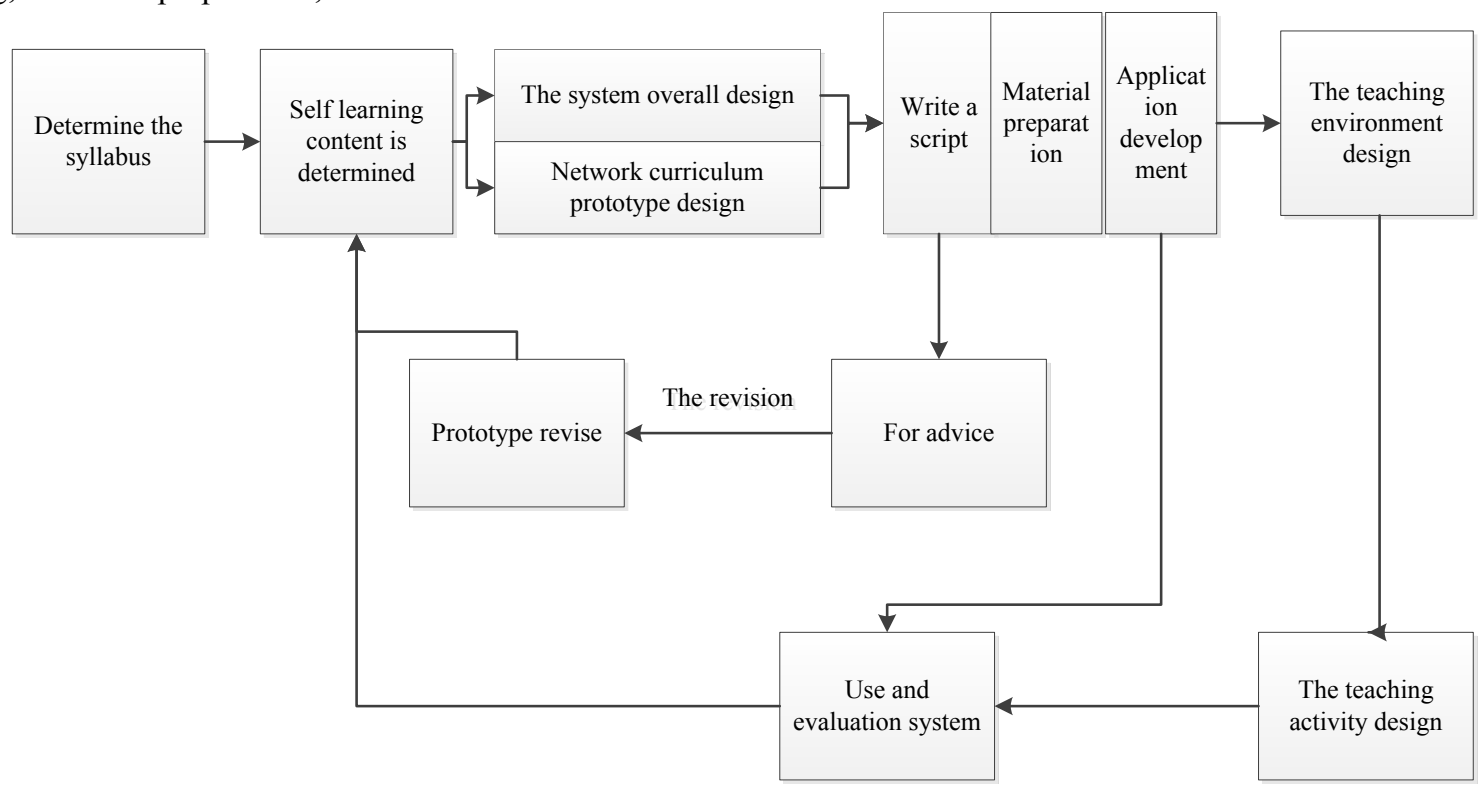

Figure 4. The flow chart of network curriculum development

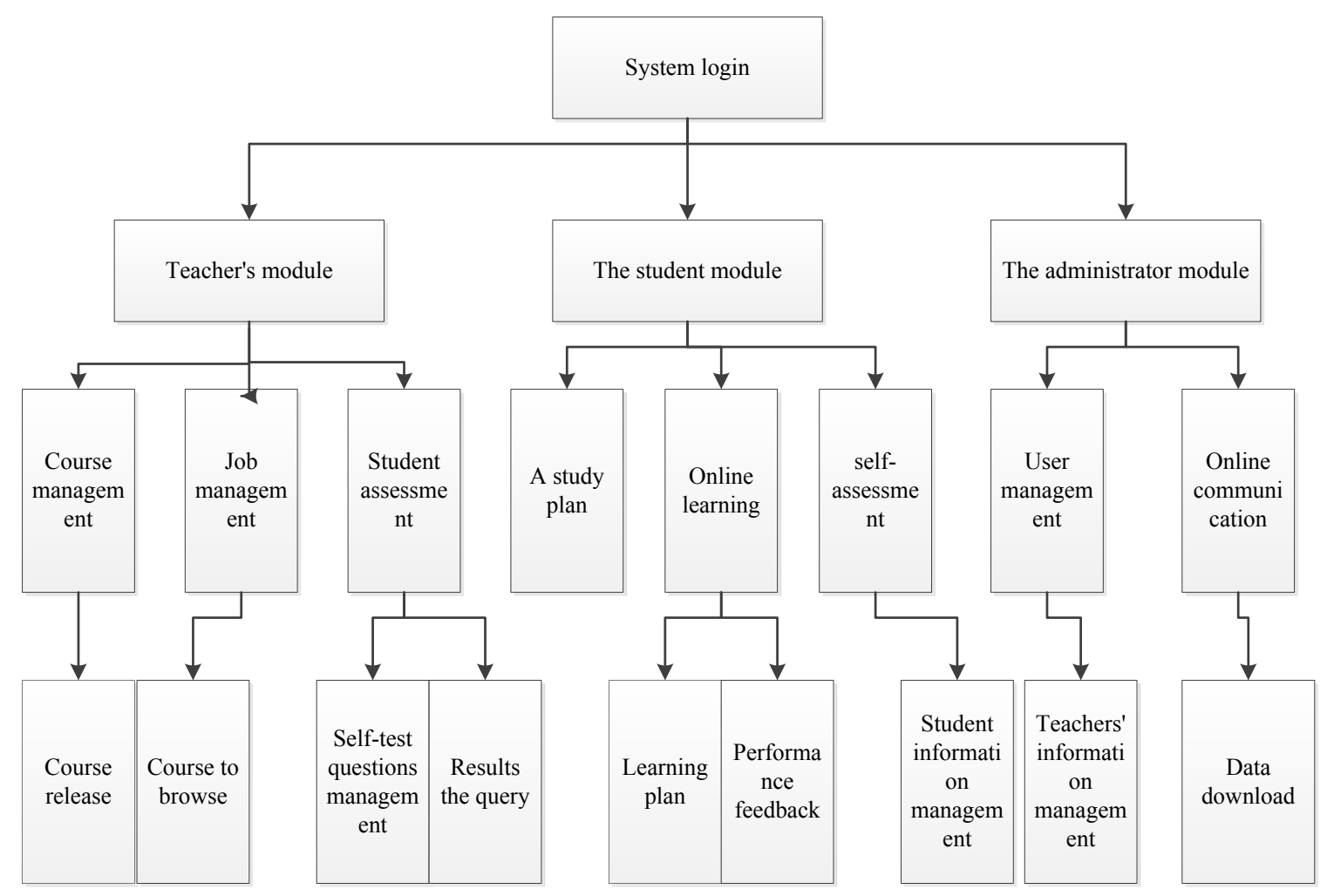

Figure 5. The whole body function module chart of the network active learning platform 


\section{The overall functions of network active learning plat- form}

The system is divided into three functional modules (teacher module, student module, administrator module) according to the noted classification of application objects before. At the same time, as the online communication function is a common area, the online exchange module is also used as an independent sub-module. The overall system of the function module of the network active learning platform is shown in Fig. 6.

The description of each function module in the system is shown in the following content:

\section{Teacher module}

The module is divided into six sub-modules: announcement management, course management, task management, student evaluation, online $\mathrm{Q} \& \mathrm{~A}$, password modification. Announcement management module is mainly for the teachers to release and manage the relevant information in the teaching process. Course management module is primarily for the management of active learning materials. As shown in Fig. 8, teachers can save the active learning content of each course unit. Task management module is largely for the releasing and maintenance of work information, as well as the evaluation of the student's homework. Student evaluation is mainly about the evaluation and results' recording based on the students' active learning time and the status of works. Test management function module is shown in Fig. 8. Online Q \& $A$ is mainly about information exchange in the exchange area with students. The password modification module is mostly designed with regard to the security of the platform.

\section{Student module}

The module is divided into six sub-modules: learning plan, online learning, online questions, work submission, self-evaluation, password modification. Learning plan module is mainly about determining the content and modifying the corresponding learning plan based on their own choice of active learning curriculum. Online learning module is mainly designed for students to acquire the online active learning content as well as record the learning time and learning experience. Online questions module is about putting forward the problems in the process of learning through online communication. Job submission module is mainly about completing the assignments and subsequent submission. Self-evaluation module is for the students to carry out online test of related knowledge after a period of learning so as to test the active learning effect and to record the test time and results as well.

\section{Administrator module}

This module is mainly for the management and online communication management of teachers' information and students' information, as well as the maintenance of backstage database. In order to improve the security of the system, the basic information of teachers and students are directly imported into the database by the administrator. At the same time, users have the only rights to modify the personal password. Administrators can manage students' information and teachers' information respectively, which is shown in Fig. 9 and Fig. 10. They are also able to set different permissions according to the nature of the users.

Through online communication, students and teachers can communicate in real time and share information with each other with the questions raised by students being solved by teachers, which is shown in Fig. 11.

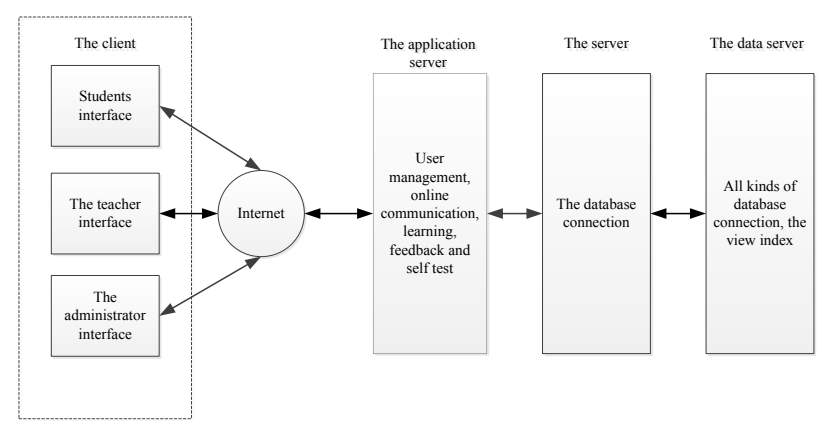

Figure 6. Network autonomous learning platform structure frame

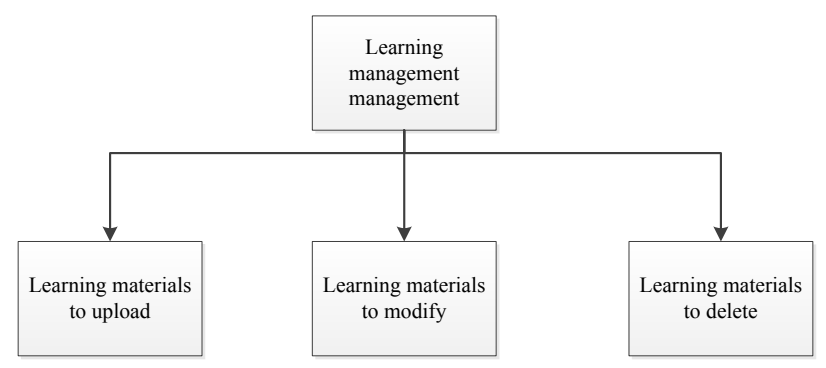

Figure 7. Learning information management module

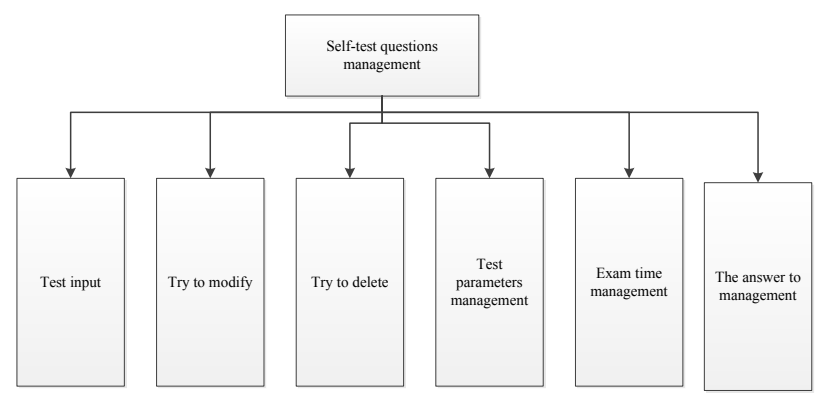

Figure 8. Self-test test question management module

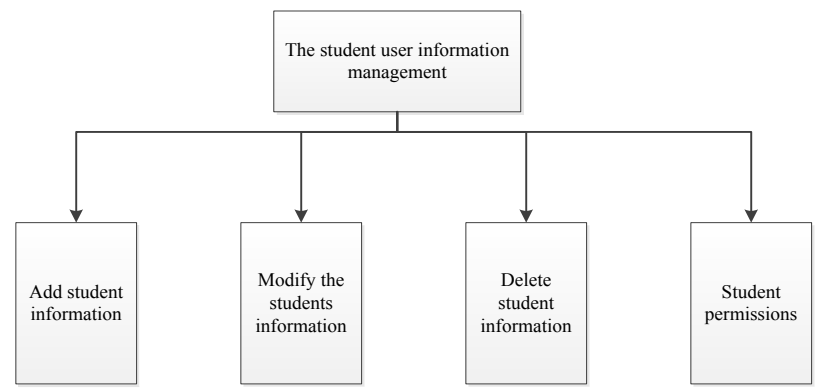

Figure 9. Students of user information management module

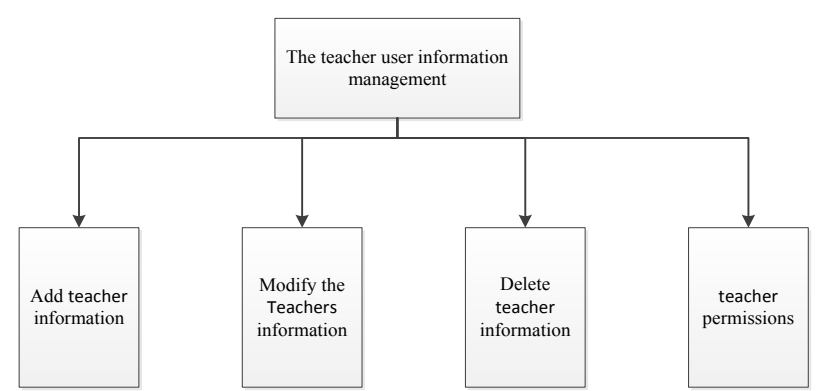

Figure 10. Teachers of user information management 


\section{Database design of active network learning platform}

1. The design steps of database

The database system is designed into six stages: the demand analysis stage, stage of conceptual structure design, stage of logical structure design, stage of database physical design, stage of database implementation, and the stage of database operation and maintenance, which is shown in Fig. 12.

2. Analysis of database requirements

By analyzing the overall requirements of the active learning platform, the system can be divided into subsystem for teachers and sub-system for students. The data items and data structures of each sub-system are mainly included in Table 1.

3. Concept design of database

According to the analysis of the main data items and data structure, as well as the abstract of reality, the basic entities of this system include teachers, students, administrators, homework, announcements, questions for tests, etc. A brief design of the part of the E-R diagram is made so as to lay the foundation for the design of the logical structure of database. Parts of the E-R figure are shown in Fig. 13.

TABLE I.

THE DATABASE TABLE

\begin{tabular}{|c|c|c|}
\hline The serial number & The name & Instructions \\
\hline 1 & Teacher's table & Teachers' basic information \\
\hline 2 & Students table & The administrator basic information \\
\hline 3 & The administrator table & Announcement of the basic information \\
\hline 4 & Announcement of the table & Study plan basic information \\
\hline 6 & Learning schedule & Basic information about job \\
\hline 7 & The author table & Try the basic information \\
\hline 8 & Test table & Online user basic information \\
\hline 9 & Online user information & Questions about the basic information
\end{tabular}

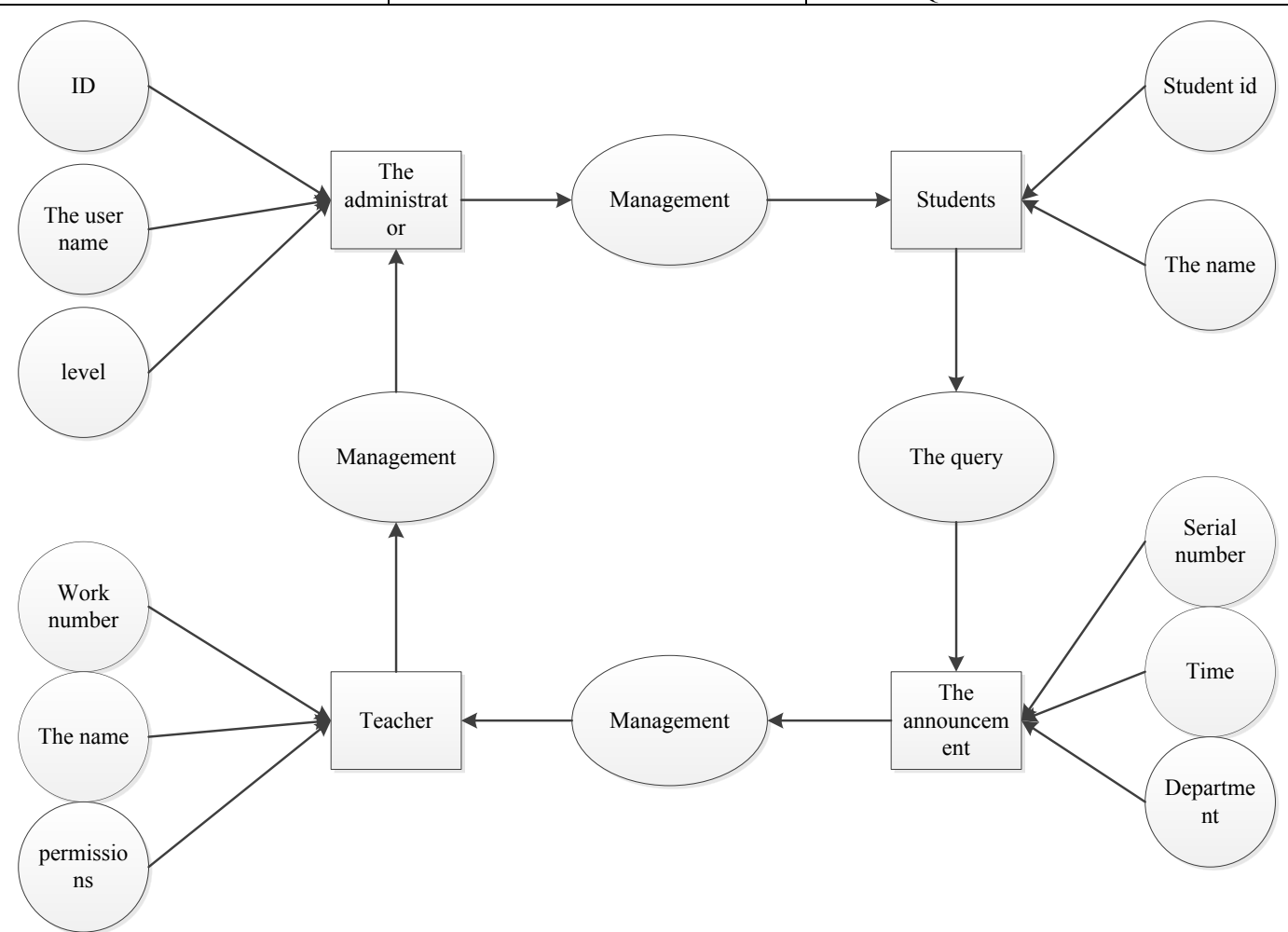

Figure 13. Users, information management, E-R diagram 


\section{CONCLUSION}

The following conclusions can be obtained through the construction of active learning mode and the design and implementation of active learning platform in computer network:

1. The active learning in computer network environment can meet the requirements of individual learning.

The active learning in computer network environment that enables learners to acquire more initiative will allow students to learn according to their favorite ways so as to stimulate students' learning potential and meet their learning needs to the largest extent.

2. The active learning in computer network environment is conducive to cultivating the innovative ability and scientific attitude of learners.

In the network-based active learning process, their attitude is changed from being passive to active, which requires them to boldly innovate the way that they accept the knowledge and demonstrate something scientifically. The process of selecting information must be careful and rigorous. From this process, they have trained their attitude towards science.

3. Active learning in the computer network environment can effectively improve the learning efficiency of students.

Under the computer network environment, with rich and various learning resources, learners can be fully mobilized with a variety of senses to understand the contents of the study in a full range and from multiple perspectives. In this way, it is easy to form in-depth understanding and memory.

4. The active learning platform in the network needs to be further improved.

Due to the lack of hardware and software infrastructure, the network active learning platform is imperfect. However, with the advancement of technology, we are able to adopt more advanced and effective methods to develop and utilize it.

\section{REFERENCES}

[1] R. Hart, "Language Study and the PLATO System", Studies in Language Learning, Vol.3, pp.1-24, 1981.

[2] K. Ahmad, G. Corbett, and M. Rogers, "Computers, language learning and language teaching", Cambridge University Press Cambridge, 1985.

[3] C.A. Chapelle. "The Spread of Computer-assisted Language Learning", Language Teaching, Vol.43, pp. 66-74, 2010. http://dx.doi.org/10.1017/S0261444809005850

[4] M. Levy, P. Hubbard, "Why Call CALL "CALL"?", Computer Assisted Language Learning, Vol.18; pp.143-149, 2005.

[5] M.D. Bush, R.M. Terry, "Technology-enhanced Language Learning”, National Textbook Company, 1997.

[6] G. Davies, D. Steele, "Micros in Modern Languages, Educational Computing", Vol.3, pp.30-31, 1982.

[7] J.R Arias, N.B. Yoma, and H. Vivanco, "Automatic Intonation Assessment for Computer Aided Language Learning, Speech Communication", Vol.52, pp.254-267, 2010. http://dx.doi.org/10.1016/j.specom.2009.11.001

[8] E.Atwell, P.Howarth, and C. Souter, "The ISLE Corpus: Italian and German Spoken Learner's English", International Computer Archive of Modern and Medieval English Journal, Vol.27, pp.5-18, 2003.
[9] J.Dalby, D.Kewley-Port, "Explicit Pronunciation Training Using Automatic Speech Recognition Technology", CALICO journal, Vol.16, pp. 425-445, 1999.

[10] M.Duong, J.Mostow, and S. Sitaram, "Two Methods for Assessing Oral Reading Prosody", ACM Transactions on Speech and Language Processing (TSLP), Vol.7,pp.14-26, 2011. http://dx.doi.org/10.1145/1998384.1998388

[11] H.Franco, L. Neumeyer, V. Digalakis, "Combination of Machine Scores for Automatic Grading of Pronunciation Quality", Speech Communication, Vol.30, pp.121-130, 2000 http://dx.doi.org/10.1016/S0167-6393(99)00045-X

[12] L.Neumeyer, H. Franco, V. Digalakis, "Automatic Scoring of Pronunciation Quality", Speech Communication, Vol.30, pp.83-93, 2000. http://dx.doi.org/10.1016/S0167-6393(99)00046-1

[13] S.Wei, G.P. Hu,Y. Hu, "A New Method for Mispronunciation Detection Using Support Vector Machine Based on Pronunciation Space Models" , Speech Communication, Vol.51,pp.896905,2009. http://dx.doi.org/10.1016/j.specom.2009.03.004

[14] C.Chapelle. "Multimedia CALL: Lessons to be Learned from Research on Instructed SLA", Language Learning and Technology, Vol.2, pp.22-34, 1998.

[15] M.A. Anusuya, S.K. Katti, "Speech Recognition by Machine: A Review", International Journal of Computer Science and Information Security (IJCSIS), Vol.6,pp.181-205,2009.

[16] K.H. Davis, R. Biddulph, and S. Balashek, "Automatic Recognition of Spoken Digits", Journal of the Acoustical Society of America, Vol.24,pp.637-642,1952. http://dx.doi.org/10.1121/1.1906946

[17] D.B. Fry, "Theoretical Aspects of Mechanical Speech Recognition", Journal of the British Institution of Radio Engineers, Vol.9, pp.211-218, 1959. http://dx.doi.org/10.1049/jbire.1959.0026

[18] F. Itakura, "Minimum Prediction Residual Principle Applied to Speech Recognition", IEEE Transactions on Acoustics: Speech and Signal Processing, Vol.23, pp.67-72, 1975. http://dx.doi.org/10.1109/TASSP.1975.1162641

[19] D. Sakai,S. Doshita, "Phonetic Typewriter", Journal of the Acoustical Society of America, Vol.33,pp.1664-1664,1961. http://dx.doi.org/10.1121/1.1936652

[20] K. Nagata, Y. Kato, and S. Chiba, "Spoken Digit Recognizer for Japanese Language", Journal of the Audio Engineering Society, Vol.12, pp.336-342, 1964.

[21] C.S. Myers, L.R. Rabiner, "A Level Building Dynamic Time Warping Algorithm for Connected Word Recognition", IEEE Transactions on Acoustics, Speech and Signal Processing, Vol.29, pp.284-297, 1981. http://dx.doi.org/10.1109/TASSP.1981.11635 $\underline{27}$

[22] L.R. Rabiner, "A Tutorial on Hidden Markov Models and Selected Applications in Speech Recognition", Proceedings of the IEEE, Vol.77, pp.257-286, 1989. http://dx.doi.org/10.1109/5.18626

[23] I. Mporas, T. Ganchev, and N. Fakotakis, "Speech Segmentation Using Regression Fusion of Boundary Predictions", Computer Speech and Language, Vol.24, pp.273-288, 2010. http://dx.doi.org/10.1016/j.csl.2009.04.004

[24] N.U. Nair, T.V. Sreenivas, "Joint Evaluation of Multiple Speech Patterns for Speech Recognition and Training", Computer Speech and Language, Vol.24, pp.307-340, 2010. http://dx.doi.org/10.1016/j.csl.2009.05.001

\section{AUTHOR}

Jingfang $\mathbf{W u}$, She received her master's degree in foreign language literature in 2007 from Xiangtan University. Now she is a lecturer in Hunan City University. Her current research interests include cognitive linguistics and college English teaching. (email: smile7178@163.com).

This paper was supported by Hunan Educational Planning Project in 2015: Research on Application of "Flipped Class" in Chinese College English Teaching (XJK015BGD013). Submitted 16 July 2016. Published as resubmitted by the author 22 August 2016. 